\title{
SELECTIVE ADSORPTION OF THE VAPOR PHASE COMPONENTS OF CIGARETTE SMOKE BY ACTIVATED CARBON FIBERS
}

\author{
By Atsushi Tokida, Taeko Toda and Kazuo Maeda \\ (Central Research Institute, Japan Tobacco Inc., \\ 6-2, Umegaoka, Midori-ku, Yokohama 227, Japan)
}

\begin{abstract}
Adsorption of the components in the vapor phase of cigarette smoke by activated carbon fibers (ACF) with micropore radii from 8 to $29 \AA$ was measured in order to study the relation between the adsorption efficiencies and the physical properties of ACFs. The adsorption efficiency increased with the size of the micropores and, with the exception of a few components, all ACFs have high adsorption ability for high boiling point components such as limonene. An ACF having a micropore radius of $8 \AA$ showed an extremely low adsorption ability and an ACF having micropore radius of $10 \AA$ uniformly adsorbed the components in the vapor phase. When compared with the semivolatile components, the molecular sieving effect and the competitive adsorption due to the difference of the boiling points were clearly observed. The competitive adsorption was thought to be the main reason for the dynamic change of adsorption with puffing. Consequently, the possibility was recognized that an increase in the amount of ACFs having wide micropores decreased the adsorption efficiency of the low boiling point components.
\end{abstract}

\section{INTRODUCTION}

The vapor phase components in cigarette smoke play an important role in the taste and flavor of a cigarette as do the semivolatile components in the particulate phase. The effects of the micropore distributions of ACFs on the reduction efficiency of the semivolatiles, tar and water by ACF filters were examined in a previous paper ${ }^{1)}$. It was found that the increase of micropore radius had opposite effects on tar and water reduction, and that molecular sieving and competitive effects influenced the reductions and the selectivity values for the semivolatile components.

Sawada et al. $^{2}$ ) examined the relation between the amount of activated carbon in cigarette filters and the delivery of the vapor phase components. They reported negative adsorption during the last few puffs in the case of filters with a small amount of activated carbon added. Maeda et al. ${ }^{3)}$ studied the adsorption efficiency of smoke components by activated carbons of varying properties which were made from various raw materials. However, systematic studies about the effects of the physical properties of adsorbents on the removal of cigarette smoke have not yet been made. As mentioned in the previous paper, the effect of micropore radius on the adsorption of the vapor phase components, as weil as the reduction of the semivolatiles, has not been elucidated. Using ACFs of varied micropore distributions, the relation between the micropore radii and the adsorption of the components of the vapor phase in cigarette smoke is discussed in this paper.

\section{EXPERIMENTAL}

\section{ACF}

Five kinds of Kuractive ACF, made from phenolic resin, were supplied by Kuraray Chemical Inc. Four of which were of the felt type and the same as those used in the previous paper ${ }^{1)}$ (ACF-B, $-C,-D$ and $-E)$. The remaining one (ACF-F) was fiber type. The mean micropore radius, pore volume and specific surface area of ACF-F were $2.9 \mathrm{~nm}, 1.10 \mathrm{ml} / \mathrm{g}$ and $2800 \mathrm{~m}^{2} / \mathrm{g}$, respectively. These values of the other ACFs were listed in the 
previous paper ${ }^{1)}$. Before use ACF-F was chopped up and became like cotton wool in appearance.

Cigarette and smoking

The cigarettes used, the method of applying the ACFs to the filter and the smoking conditions were all the same as those in the previous paper ${ }^{1)}$. At the 2 nd, 5 th, 8 th, 11 th or 14 th puff, the smoke which passed through a glass fiber filter (Toyo Roshi, GB100R), this fraction of the cigarette smoke is defined as the vapor phase, was admitted into a gas sampling tube, $2 \mathrm{ml}$ in volume.

Analysis and identification of the smoke components

The vapor phase components in the gas sampling tube were analyzed by a Shimadzu GC-9A gas chromatograph equipped with a flame ionization detector and a glass capillary column $(0.25 \mathrm{~mm}$ i.d. $\times 60 \mathrm{~m}$ ) coated with Reoplex 400 . The column temperature was programmed to be held at $0^{\circ} \mathrm{C}$ for the initial $10 \mathrm{~min}$, then was raised from 0 to $180^{\circ} \mathrm{C}$ at a rate of $2^{\circ} \mathrm{C} / \mathrm{min}$. The flow rate of nitrogen, the carrier gas, was $0.6 \mathrm{ml} / \mathrm{min}$ and the split ratio was $1: 60$. The chromatogram was recorded with a Shimadzu Chromatopac C-R2AX. The GC/MS measurements were carried out on a Nippon Electric Varian Model TE-600 mass spectrometer. Identification of peaks of the chromatogram was carried out by comparing the mass spectra and GC retention times with those of authentic compounds.
The chromatogram of the vapor phase of genuine cigarette smoke is shown in Fig. 1 . The components which have been identified are listed in Table 1. Those with peak numbers greater than 74 are also found among the semivolatiles ${ }^{1)}$. The boiling points of the components in Table 1 range from 21 to $175^{\circ} \mathrm{C}$ and the molecular weights from 40.05 to 136.23 .

Table 1 Components identified in the vapor phase of the cigarette smoke

\begin{tabular}{cl}
\hline Peak No. & Component \\
\hline 8 & Isoprene \\
14 & Acetaldehyde \\
21 & Furan \\
24 & Isobutyraldehyde \\
25 & Acetone \\
28 & Acrolein \\
33 & 2-Butanone \\
38 & Benzene \\
41 & 1-Buten-3-one \\
44 & 2,5-Dimethylfuran \\
47 & Acetonitrile \\
50 & $2,3-$ Butanedione \\
52 & Propionitrile \\
58 & Toluene \\
66 & $2,3-$ Pentanedione \\
74 & Ethylbenzene \\
77 & p-Xylene \\
78 & m-Xylene \\
85 & a-Xylene \\
87 & Limonene \\
\hline
\end{tabular}

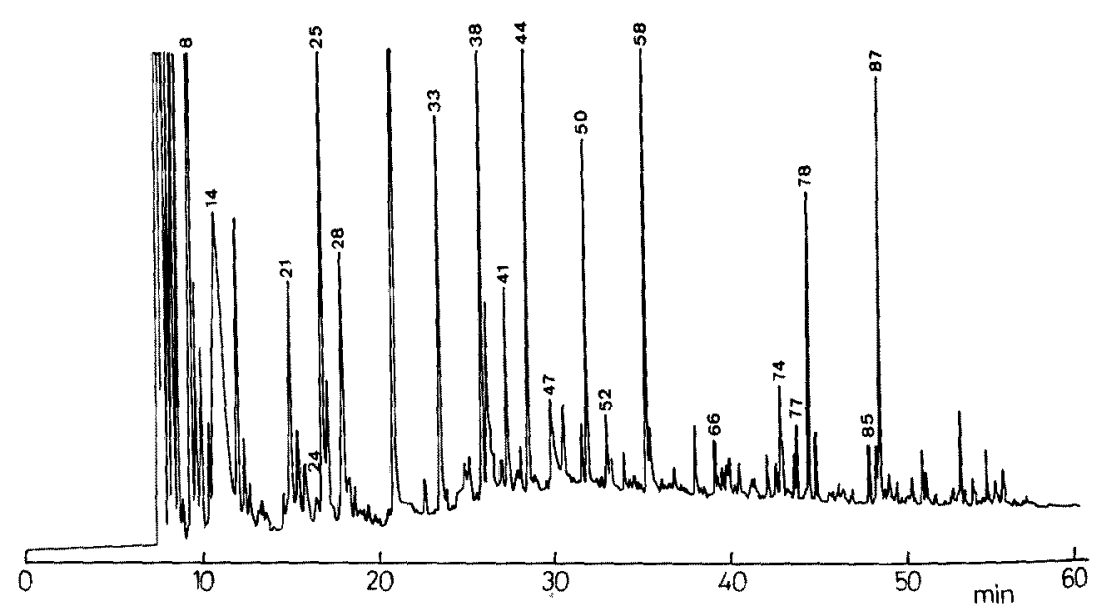

Fig. 1 Gas chromatogram of the vapor phase components of the cigarette without the ACF filter. 


\section{Adsorption efficiency}

The adsorption efficiency of a component $i$ (Ein) at puff number $n$ is defined by eq. (1).

$$
\operatorname{Ein}=\frac{100\left(H_{\text {inc }}-H_{\text {ins }}\right)}{H_{\text {inc }}}
$$

Where $H_{\text {inc }}$ and $H_{\text {ins }}$ are the relevant peak heights of a component $i$ at the $n$-th puff for cigarettes without $\mathrm{ACF}$ and with $\mathrm{ACF}$, respectively. The adsorption efficiency for a whole cigarette was calculated using eq. (1) in which $H_{\text {inc }}$ and $H_{\text {ins }}$ were substituted by the values of the summations of the peak heights of the five puffs measured in accordance with the assumption that the summed values were proportional to the real amounts of the component $i$ for a whole cigarette.

\section{RESULTS AND DISCUSSION}

\section{Variation of adsorption with puff number}

Variations of adsorptions of acetaldehyde, acetonitrile and furan, of which molecular weights or boiling points are in the lowest group are shown in Fig. 2. Extreme differences in adsorption efficiency were found between ACF-B and the others. ACF-B adsorbs acetaldehyde and acetonitrile in the first half of smoking and, further, negative adsorption due to desorption was not found in the last half. But furan was not appreciably adsorbed. For ACF-C $\sim-F$, the adsorption efficiencies do not differ as much as the specific surface areas or the mean pore radii do. The effect of the wide micropore diameter of ACF-F is clearly observed in the adsorption of acetaldehyde. Comparing the components in Fig. 2 with those of higher boiling points shown in Figs. 3 and 4, the adsorptions by ACF-C $\sim-F$ decreased early in the first or intermediate stage of puffing and the efficiencies changed drastically during the process of smoking. In addition, the high adsorption in the first half gave high negative adsorption in the last half. As the molecular weights of acetaldehyde and acetonitrile are almost the same but the boiling point of acetonitrile is about $60^{\circ} \mathrm{C}$ higher than that of acetaldehyde, the difference in adsorption between these two components arises from the difference of the boiling points. Comparing acetonitrile with 1-buten-3-one (Fig. 3), whose boiling points are almost the same, the component of higher molecular weight is adsorbed more effectively.

Variations of adsorptions with the puff number for isoprene, 2-butanone and 1-buten-3-one are shown in Fig. 3. They are the components of intermediate molecular weights and boiling points in the vapor phase. The adsorption by ACF-B for these three components is low but higher than that for furan. As shown in Fig. 2, ACF-F exceeds $-C$ in adsorption during the first half and comes close to $-\mathrm{D}$ and $-\mathrm{E}$.

The decrease of the adsorption efficiency during

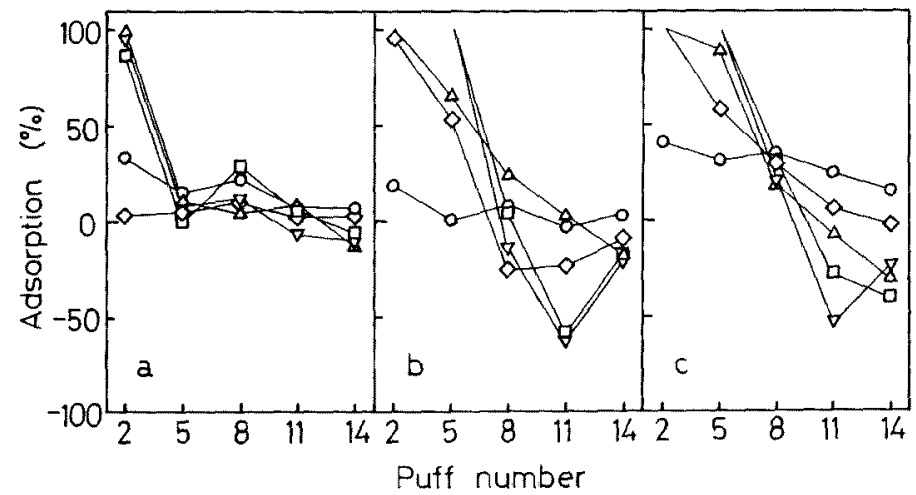

Fig. 2 Variation of adsorption with puff number.

a) Acetaldehyde, b) Furan, c) Acetonitrile,

$O$ ACF-B $(60 \mathrm{mg}), \triangle-C(20 \mathrm{mg}), \nabla-D(20 \mathrm{mg}), \square-\mathrm{E}(20 \mathrm{mg})$,

$\diamond-F(20 \mathrm{mg})$

Symbols which represent the adsorptions of $100 \%$ are

omitted to avoid complication. 


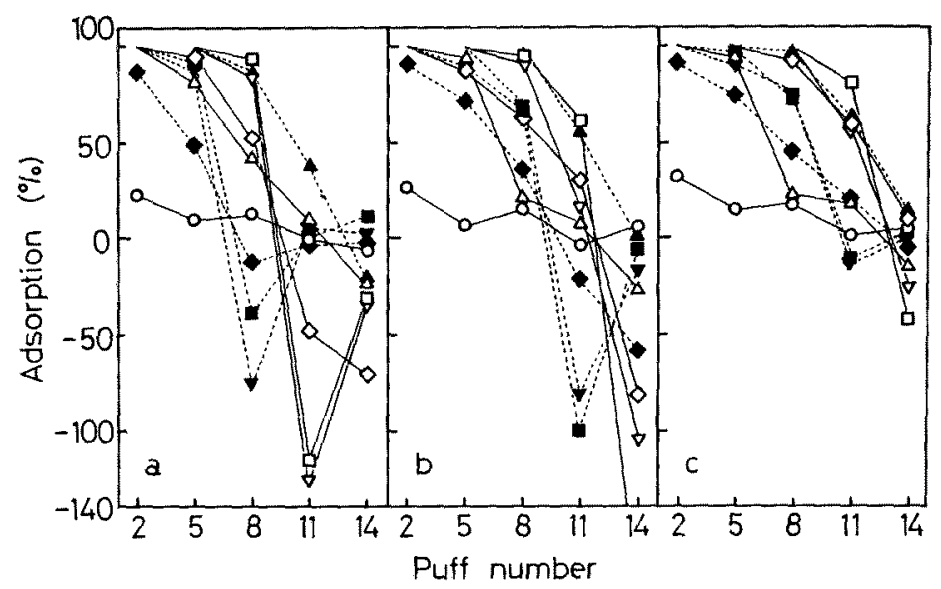

Fig. 3 Variation of adsorption with puff number.

a) Isoprene, b) 2-Butanone, c) 1-Buten-3-one, $O \mathrm{ACF}-\mathrm{B}(60 \mathrm{mg}), \triangle \mathrm{C}(20 \mathrm{mg}), \triangle-\mathrm{C}(50 \mathrm{mg}), \nabla-\mathrm{D}(20 \mathrm{mg})$,

$\nabla-\mathrm{D}(10 \mathrm{mg}), \square-\mathrm{E}(20 \mathrm{mg}), \mathbf{E}-\mathrm{E}(10 \mathrm{mg}), \diamond-\mathrm{F}(20 \mathrm{mg})$,

- F (10mg)

Symbols which represent the adsorptions of $100 \%$ are omitted to avoid complication.

the last half depends on the physical properties of both ACFs and the smoke components. ACF-D and $-E$ which are the most effective during the first half show the largest negative adsorption during the last half. It is worth while noticing that isoprene showed the largest negative adsorption at the 11 th puff by using $20 \mathrm{mg}$ of ACF-D, -E, while 2-butanone and 1-buten-3-one showed the largest negative adsorption at the 14th puff. With the addition of $10 \mathrm{mg}$, the largest negative adsorption shifted 3 puffs earlier for all the three components. This tendency has also been observed for furan and acetonitrile with ACF-D and -E, but the information is not shown in Fig. 2. By the change of adsorption during the process of smoking, it happens in some cases that the increase of the amount of the adsorbent in the filter does not lower the concentration of the smoke components in the last half of smoking.

Variations of the adsorptions for toluene, $\mathrm{m}$ xylene and limonene, all of which have boiling points higher than $100^{\circ} \mathrm{C}$, are shown in Fig. 4 . ACF-B showed a similar low ability to those in Figs. 2 and 3 but is more effective in Fig. 4 . The difference in adsorption between ACF-C and -D becomes larger than those shown in Fig. 3. For even these high boiling point components, ACF-F has lower efficiency than - $E$ in spite of its larger specific surface area. Therefore, it can be seen that adsorption by the excessively wide micropores, is not very effective for the vaporous components.

In most cases, adsorptions of $m$-xylene and limonene by ACF-D, $-E$ and $-F$ became positive during the last half of smoking when only $10 \mathrm{mg}$ was added. For limonene, especially, an adsorption of $50 \%$ or greater was found even during the last puff. This efficiency obtained for the vapor phase exceeds the value of reduction for limonene in the semivolatiles. As mentioned above, ethylbenzene, o-, $\mathrm{m}$ - and $\mathrm{p}$-xylene and limonene were also found in the semivolatiles, and the amounts of these components distributed in the semivolatiles can not be neglected ${ }^{4}$ ). However, it is thought that the adsorption obtained by the vapor phase directly reflects the behavior of these components at the time when they pass through the ACF layer as vapor.

Comparing the adsorption behavior by the ACFs shown in Figs. $2 \sim 4$, it can be seen that the micropore distribution has a serious influence on the variation of the efficiency. ACF-B of which the micropores are the narrowest, adsorbed components of the lowest molecular weights such as acetaldehyde and acetonitrile most effectively 


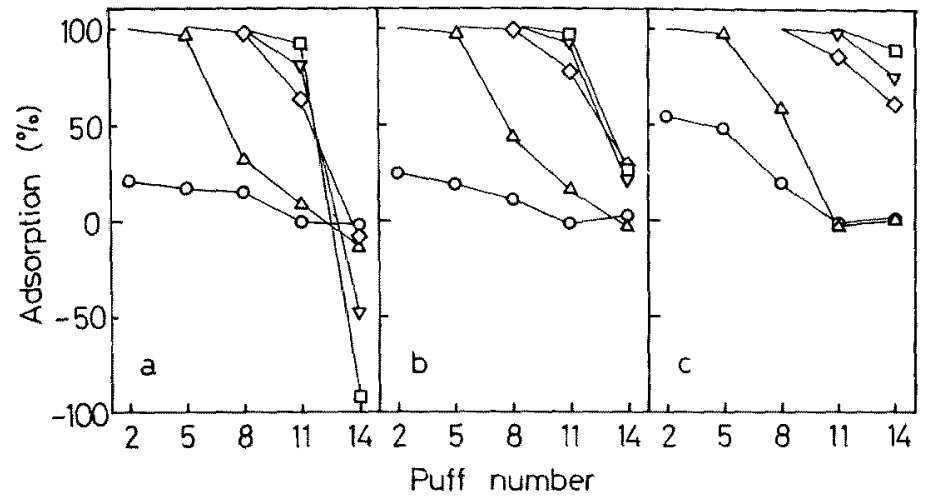

Fig. 4 Variation of adsorption with puff number.

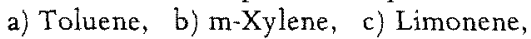

$\bigcirc$ ACF-B (60mg), $\triangle-C(20 \mathrm{mg}), \nabla-D(20 \mathrm{mg}), \square-\mathrm{E}(20 \mathrm{mg})$,

$>-F(20 \mathrm{mg})$

Symbols which represent the adsorptions of $100 \%$ are

omitted to avoid complication.

during the initial few puffs, in addition to the higher molecular weight components such as limonene and m-xylene. Moreover, it captured smaller amounts of the components at the initial period and released at the final than the other ACFs. The mean diameter of the micropore of $A C F-B$ is $16 \AA$ and which is wide enough to diffuse the components in the vapor phase. And although the difference between ACF-B and -C is only $4 \AA$ in micropore diameter and $460 \mathrm{~m}^{2} / \mathrm{g}$ in specific surface area, their adsorption abilities differ extremely.

In the case of granular activated carbon of about $0.5 \mathrm{~mm}$ diameter and of which mean micropore and specific surface area are similar to those of ACF-B, about $60 \%$ or more adsorption of the low boiling point components such as acetaldehyde and isoprene was achieved by addition of about $50 \mathrm{mg}^{5)}$. Such a marked difference in the adsorption due to the size of micropore diameter was not found for the activated carbons. Activated carbons have mesopores and macropores besides micropores, while ACFs have micropores directly on their surface. The rates of the diffusion of adsorbates in ACF is over ten times faster than in activated carbons ${ }^{6}$ ). Therefore, the difference in the rate of diffusion between ACFs and activated carbons have great effect on the adsorption efficiency of cigarette smoke. As distinct from activated carbons, the radius of micropores rather than the specific surface areas is considered to contribute significantly on the adsorption of the ACFs. Of course, the other components in the whole smoke may also have more serious effects on ACF-B among ACFs.

When the boiling points of the components become high, the difference of the adsorption efficiency between ACF-C and -D becomes large. That is to say, adsorption by ACF-C does not change that much with the boiling points of the components. Considering the physical properties of ACF-D and -E, they differ $8 \AA$ in micropore diameter and $580 \mathrm{~m}^{2} / \mathrm{g}$ in specific surface area. Yet, the adsorption efficiency of two ACFs is rather similar. The effect of the micropore is clearly revealed by ACF-F. It has micropores $26 \AA$ wider than - $E$ but its specific surface area is only $30 \mathrm{~m}^{2} / \mathrm{g}$ greater. Therefore, the lower efficiency of ACF-F compared with - $E$ is considered to be caused mainly by the micropores. By paying attention to the micropore radii, it can be seen that the adsorption efficiencies vary dynamically in the narrow range from 8 to $12 \AA$ and increasing in micropore radii over $12 \AA$ has relatively little effect on the behavior. Although the specific surface area of the ACFs used in this work are large, their influence on the adsorption is not so great.

Adsorption of the vapor phase components during the process of smoking varies to a great 
degree compared with that of the semivolatiles. Williamson and Allman ${ }^{7)}$ have reported that the negative adsorption during the last few puffs is caused by an increase in the smoke temperature. In the previous paper ${ }^{1}$, the same tendency was found but was considered to be due to the competition among the semivolatiles of various boiling points. As shown in Figs. $2 \sim 4$, the effect of competition rather than rise in temperature is more clearly recognized in the vapor phase than in the semivolatiles, because the temperature of the smoke passing through the ACF layer is still near ambient temperature ${ }^{8)}$ during the intermediate stage of smoking.

It may be concluded that the variation of adsorption with puff number arises from saturation of adsorptive volume with the progress of smoking and the competitive adsorption arising from the differences in both of boiling points of the components and the affinities to the ACFs. Moreover, the molecular sieving effect is expected to vary according to physical properties of the adsorbents in a system of cigarette smoke which comprises various components with a wide range of physical properties. It had been anticipated that the adsorption behavior of the ACFs would be influenced during the process of smoking by the changes in the properties of the surfaces due to the adsorbates, but definite evidence for this has not been obtained.

\section{Adsorption efficiency of a whole cigarette smoke}

In Fig. 5, the adsorption efficiencies of the vapor phase components for a whole cigarette smoke are shown. The peak numbers of the chromatogram are plotted as abscissa. ACF-E and -F showed the similar tendencies and adsorption efficiencies to those of $-D$, and the differences of the adsorptions between ACF-D, $-\mathrm{E}$ and $-\mathrm{F}$ against the abscissa were not so large as those among ACF-B, -C and -D. It is characteristic for ACF-C, as mentioned in the previous section, that it adsorbed all the components moderately, but lost the selectivities for acetaldehyde and acetonitrile. Adsorption by ACF-D become effective as the boiling points of the components rise. Therefore, the radius of $10 \AA$ is preferable in order to remove all the vapor phase components uniformly.

From Fig. 5 in the previous paper ${ }^{1)}$ and Fig. 3 in this work, it can be recognized that the ACFs act effectively on the semivolatile components of which boiling points are in the range between 100 and $200^{\circ} \mathrm{C}$.

The relation between the adsorption efficiency for whole cigarettes and the amount of ACFs are shown in Table 2. The efficiency of ACF-B increased only about $10 \%$ except for acetonitrile when three times amount of ACF was used. An increase in the amount of ACF-C showed the uniform adsorptions. ACF-D can adsorb the high

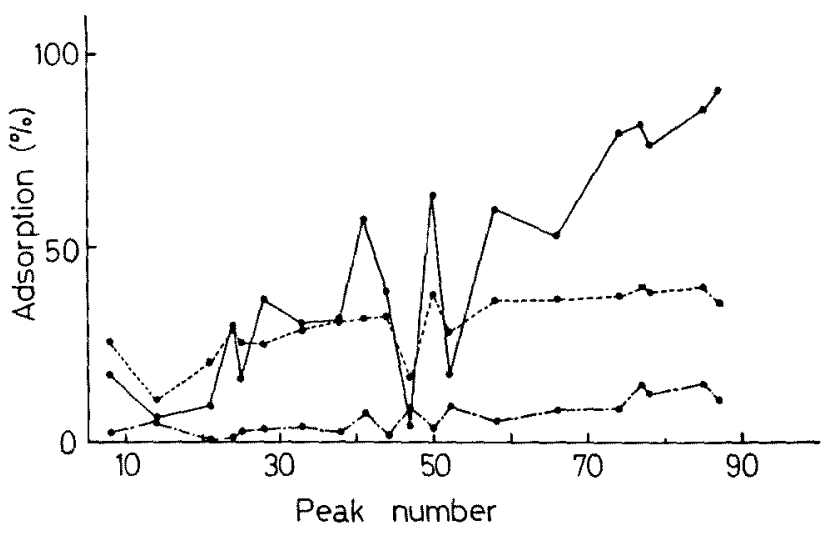

Fig. 5 Adsorptions of the vapor phase components obtained for whole cigarettes by activated carbon fibers.

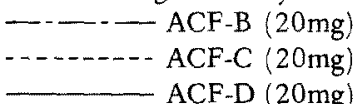


Table 2 Adsorptions of the vapor phase components by activated carbon fibers

\begin{tabular}{|c|c|c|c|c|c|c|c|c|c|c|}
\hline \multirow[t]{3}{*}{ Component } & \multicolumn{10}{|c|}{$\mathrm{ACF} / \mathrm{mg}$} \\
\hline & \multicolumn{2}{|c|}{ B } & \multicolumn{2}{|c|}{ C } & \multicolumn{2}{|c|}{$\mathrm{D}$} & \multicolumn{2}{|c|}{$E$} & \multicolumn{2}{|c|}{$F$} \\
\hline & 20 & 60 & 20 & 50 & 10 & 20 & 10 & 20 & 10 & 20 \\
\hline Isoprene & 2.0 & 6.7 & 25.8 & 56.6 & 13.0 & 17.2 & 23.7 & 22.3 & 16.4 & 17.3 \\
\hline Acetaldehyde & 5.3 & 18.6 & 10.2 & 34.8 & 5.3 & 12.2 & 17.0 & 15.0 & 10.8 & 4.9 \\
\hline Furan & 1.0 & 5.2 & 20.2 & 46.0 & 9.5 & 9.4 & 17.0 & 15.6 & 13.7 & 8.6 \\
\hline Acetone & 2.7 & 9.6 & 25.5 & 55.0 & 19.7 & 16.2 & 24.6 & 17.9 & 18.6 & 17.8 \\
\hline 2-Butanone & 3.9 & 10.4 & 28.9 & 65.1 & 23.2 & 30.0 & 21.1 & 11.1 & 13.6 & 35.9 \\
\hline Benzene & 2.5 & 11.2 & 30.8 & 61.8 & 30.4 & 24.8 & 31.0 & 16.5 & 20.8 & 31.2 \\
\hline 1-Buten-3-one & 7.5 & 16.2 & 31.6 & 66.0 & 44.2 & 56.9 & 46.8 & 58.7 & 36.5 & 65.1 \\
\hline Acetonitrile & 13.7 & 28.3 & 16.5 & 55.0 & 15.2 & 3.9 & 27.8 & 17.7 & 23.7 & 21.7 \\
\hline 2,3-Butanedione & 3.7 & 12.3 & 38.4 & 60.1 & 47.0 & 62.9 & 50.1 & 63.0 & 41.3 & 70.1 \\
\hline Propionitrile & 9.1 & 21.0 & 27.9 & 62.4 & 19.9 & 17.9 & 18.0 & 7.7 & 13.2 & 25.8 \\
\hline Toluene & 5.4 & 15.4 & 36.3 & 76.5 & 36.8 & 59.9 & 43.0 & 51.6 & 37.0 & 65.2 \\
\hline 2,3-Pentanedione & 8.5 & 19.2 & 36.3 & 71.4 & 37.1 & 52.8 & 41.8 & 52.4 & 39.0 & 66.0 \\
\hline Ethylbenzene & 8.7 & 17.3 & 37.2 & 83.9 & 60.2 & 79.3 & 49.1 & 83.3 & 46.5 & 77.0 \\
\hline m-Xylene & 12.4 & 16.0 & 38.6 & 85.3 & 66.9 & 76.3 & 59.6 & 79.1 & 51.2 & 75.0 \\
\hline Limonene & 10.8 & 20.6 & 35.5 & 91.6 & 86.6 & 90.8 & 86.3 & 95.9 & 69.3 & 83.4 \\
\hline
\end{tabular}

boiling point components in the vapor phase only when the smaller amount is used, but the adsorption of the low molecular weight and low boiling point components such as acetonitrile and furan decreased comparing with that for ACF-C. It is characteristic, moreover, that, for some components such as acetone and benzene, the increase of the ACF amount decreases the efficiency. This inverse tendency is more pronounced for ACF.E.

As discussed in the previous section, the puff by puff adsorptions vary greatly when both the boiling points and the molecular weights become low because of the adsorptive competition with less volatile components. Therefore, this inverse tendency should be found in the ACFs that specifically adsorb the high boiling point components. The temperature of the smoke that enters the ACF layer increases to a maximum of about $80^{\circ} \mathrm{C}$ but the ambient temperature is maintained except for final few puffs ${ }^{8}$. Therefore, the effect of temperature on the variation of the adsorption should not exceed the effect of the competition in this work.

The specific surface areas of the ACFs used in the experiment increase with the mean micropore radii. When the size of the micropore become wide, the rate of diffusion in the micropores increases but the energetical stability for the adsorbate decreases ${ }^{9}$, while, the adsorptive volume increases with an increase of the specific surface area at a fixed pore radius. Consideration of these properties in relation to the experimental results leads to the following discussion.

When the radius of the micropores becomes wide, the rate of the penetration of high molecular volume components into the pores also becomes fast, while the ability of retention for the low molecular volume components decreases. Therefore, the proportion of the components being desorbed from the field of adsorption increases especially for those with low boiling points. When the specific surface area becomes large while the radius of the micropores is kept constant, the changes in the ratios of the rates of penetration for the components are not so marked but, for all the components, the resulting adsorption raised and the stability of the retention unchanged appreciably. Consequently, enlargement of the two properties is preferred to the less volatile components.

The increase of the specific surface area at a fixed micropore radius can be related qualitatively and simply to the increase of the amount used in the filter if the length of the ACF layer and its detailed construction can be neglected. When the whole smoke passes through, however, ACF captures the smoke particles, greater amount of the smoke is captured or adsorbed by ACF in upstream than by that in downstream. Therefore, adsorption ability for the vapor phase components is lowered by the captured smoke, and the ACF filter shows adsorption efficiency as if its mean 
micropore radius and specific surface area become small. By the increase of the amount added in the filter, the deterioration of the ability for a filter is lowered, adsorption efficiency for high boiling point components in the vapor phase increases, and the adsorptive substitution by competition of the smoke components occurs markedly. Consequently, conflicting experimental results were obtained concerning the relationship between the $A C F$ amounts and the adsorption efficiency. It is considered that this relationship for ACF-B or $-C$ is not necessarily the same as those for $-D,-E$ and $-F$ because these have narrow micropores which act as the molecular sievings for large molecular volume components.

Although a strict comparison of ACF-F with the others can not be made directly because the shape of the material and the method of addition are different, it can be said that ACF-F is inferior to ACF-E in adsorption ability. The reason why a decrease of the adsorption efficiency of ACF-F with an increase of its amount was found to be as follows for a few components. Micropores which are too wide, lower the effect of the differences in molecular volumes on the affinities of the various constituents in the vapor phase with ACF-F. The possibility may be also pointed out that the physical properties of the surface were changed by the adsorbates in the process of smoking. From an energetical point of view, ACF-B contrasts with $-F$ and can retain the adsorbates even during the final few puffs as shown in Figs. $2 \sim 4$. Both the energetical stability of adsorption and the molecular sieving effect for $A C F-B$ should be reflected in these figures.

If chemisorption is negligible, the radius of micropores and the specific surface area of the adsorbents used in multicomponent systems such as cigarette smoke are restricted according to the cigarette design in which a particular fraction of smoke is removed. Moreover, there exists the possibility of an increase in the concentration of specified components by increasing the amount of the adsorbent. It can be recognized, therefore, that the control of the physical properties and the amounts of the adsorbents have great influences intimately related to the taste and flavor of cigarettes.

As well as the semivolatiles, adsorptions of the vapor phase components by ACF filters can be explained on the basis of the molecular sieving and the competitive effects. It was also found that the effects of the two mechanisms on the vapor are more serious than on the semivolatiles. For activated carbon, the effects of the physical properties may not appear as remarkably as with the ACFs used in this work. It is considered, however, that the relations discussed in this work can also be applied to this commonly used adsorbent.

\section{REFERENCES}

1) A. Tokida, T. Toda and K. Maeda, Sen-i Gakkaishi, 41, T-539 (1985)

2) H. Sawada, J. Kawamoto and M. Kotani, 14th Coresta Symposium, Winston-Salem, Northcarolina, 1982

3) K. Maeda, Y. Akinaga, H. Kamoshida, Y, Matsumura, K. Kobayashi, M. Ishii, A. Ohnishi, T. Nakahata and M. Uehara, Nippon Senbai Kosha Chuo Kenkyusho Hokoku, 115, 33 (1973)

4) S. Ishiguro, Nippon Senbai Kosha Chuo Kenkyusho Hokoku, 121, 13 (1979)

5) K. Maeda, Y. Anzai, T. Sawakuri, A. Tokida T. Akagi and K. Noguchi, Nippon Senbai Kosha Chuo Kenkyusho Hokoku, 118, 183 (1976)

6) N. Ishizaki, Bunri Gijutsu, 14, 13 (1984)

7) J. T. Williamson and D. R. Allman, Beitr. Tabakforsch., 2, 263 (1964)

8) Y. Masuo, unpublished data

9) K. Kawazoe, Abstract of the Symposium on Adsorption and Reaction, $\mathrm{p}^{4}$, the Chemical Engineering Society Japan (1973) 


\title{
活性炭素瀻維によるたばこ煙中蒸気相成分の選択吸着
}

\author{
日本たばこ産業株式会社中央研究所 \\ 常田渖, 戸田妙子。前田和生
}

平均細孔半径が 8- $29 \AA$ の活性炭素瀻 (ACF) 維 い,たば己知中蒸気相成分の吸着之細孔径の関係を調べ

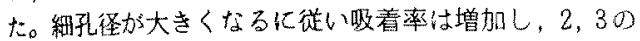

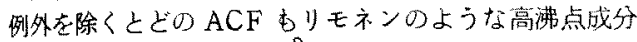

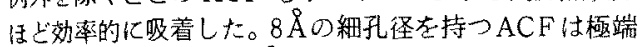

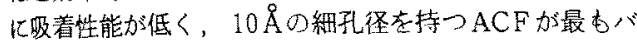
ランス良く蒸気相成分走除去することがわかった。七
ボラタイル成分と比較すると，分子篩作用や成分の沸点 差に由来寸る競合吸着がより明瞭に認められ，特に競合 吸着は吸煙の進行に伴う吸着率変化の主要な原区上考え

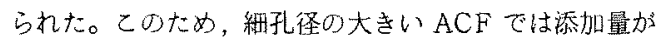
增加する上蒸気相中低沸点成分の吸着率が減少する可能 性のあるととがわかった。 